\title{
O PAPEL DA AGRICULTURA FAMILIAR PARA A DIVERSIFICAÇÃO E VALORIZAÇÃO DA PRODUÇÃO DE ALIMENTOS PÓS REVOLUÇÃO VERDE NO BRASIL
}

\section{EL PAPEL DE LA AGRICULTURA FAMILIAR PARA LA DIVERSIFICACIÓN Y VALORIZACIÓN DE LA PRODUCCIÓN DE ALIMENTOS DESPUÉS DE LA REVOLUCIÓN VERDE EN BRASIL}

\author{
${ }^{1}$ Alexandrina Benjamin Estevão de Farias
}

\section{RESUMO}

Esse artigo pretende fazer uma análise da questão da produção de alimentos, após a revolução verde, e a eficácia do direito à alimentação no país. A partir da década de 60 , a modernização do campo manteve o modelo latifundiário e monocultor no cenário agrícola brasileiro e exclui a agricultura familiar do acesso as novas tecnologias. Com isso, houve uma alteração no modelo produtivo de alimentos, reduzindo a diversidade de produtos e comprometendo o desenvolvimento da relação homem-alimento-sociedade. Haja vista que, o modo de produção de alimentos tem ligação direta à relação do homem com seu meio e com a cultura na qual está imerso. Assim, a agricultura familiar consistiria em uma maneira de exploração capaz de adaptar e persistir em ambientes com o predomínio das práticas de viés capitalista, bem como é capaz de adaptar-se às novas exigências da sociedade (efetividade do direito à alimentação, o desenvolvimento sustentável do agrícola, o combate à fome e miséria e a preservação ambiental).

Palavras-chave: Agricultura familiar, Direito à alimentação, Desenvolvimento

\section{RESUMEN}

Ese artigo pretende hacer una análisis de la cuestión de la producción de alimentos, después la revolución verde, y la eficacia del derecho a la alimentación en el país. A partir de los años 60, la modernización del campo a mantenido el modelo de los latifundios y del monocultivo en el escenario agrícola brasileiro y excluyendo la agricultura familiar del acceso a las nuevas tecnologías. Con eso, hubo una alteración en el modelo productivo de alimentos, reduciendo la diversidad de productos y comprometiendo el desarrollo de la relación hombre-alimentosociedad. Considerando que, el modo de producción de alimentos tiene ligación directa a la relación del hombre con su medio y con la cultura en la cual está inmerso. Así, la agricultura familiar consistiría en una manera de explotación capaz de adaptar y persistir en ambientes con el predominio de las prácticas de naturaleza capitalista, así como es capaz de si adaptar a las nuevas exigencias de la sociedad (efectividad del derecho a la alimentación, el desarrollo sostenible agrícola, el combate a la hambre y miseria y la preservación ambiental).

Palabras-claves: Agricultura familiar, Derecho a la alimentación, Desarollo

\footnotetext{
${ }^{1}$ Mestranda em Direito Agrário pelo Programa de Pós-Graduação em Direito Agrário na Faculdade de Direito da Universidade Federal de Goiás - UFG, Goiás (Brasil). Professora efetiva na Faculdade de Jussara, Goiás (Brasil). Email: alexandrina.benjamin@yahoo.com.br
} 


\section{INTRODUÇÃO}

Por estar diretamente relacionada com o direito à vida, a produção de alimentos talvez seja, de uma maneira geral, uma das principais preocupações da humanidade.

Não apenas pelo fato dos alimentos saciarem a fome do ser humano. A produção de alimentos, além de alimentar, remunera uma cadeia de produção, circulação e venda, bem como satisfaz a opção tecnológica, política e de investimentos que orientaram a oferta desses produtos para o consumo humano (DERANI, 2006).

Além disso, como afirma Valente (2002), ao comer nos refazemos, nos construímos, nos potencializamos nas dimensões orgânicas, intelectuais, psicológicas e espirituais, enfim, somos o que comemos e como comemos.

No entanto, apesar dos inúmeros avanços tecnológicos que o meio agrícola recebeu nos últimos anos, objetivando aumentar a quantidade e qualidade dos produtos, há sérias preocupações quanto à efetividade do direito à alimentação.

Ao analisarmos o cenário brasileiro, país que apresenta representatividade na produção de alimentos a nível mundial, percebe-se que a produção e a disponibilidade de alimentos em quantidades suficientes não são sinônimos de segurança alimentar de uma população.

A produção industrial de alimentos, distante das relações pessoais de convívio, tem retirado das relações humanas um valioso momento de desenvolvimento, que lhe é essencial, para solidez das redes de solidariedade, e cumplicidade afetiva (DERANI, 2006).

Além disso, nota-se, também, uma redução na variedade dos próprios alimentos produzidos, pois, o modelo modernamente aplicado não valoriza essa diversidade, acarretando problemas tanto de natureza alimentar, social, bem como ambiental.

A “revolução verde" implanta no Brasil, a partir da década de 60, trouxe modernização para o campo, com a consequente manutenção do modelo latifundiário e monocultor, assim como gerou a exclusão da agricultura familiar, dificultando o acesso ao processo tecnológico nascente.

No entanto, tem-se percebido que o modo de produção familiar consiste em uma maneira de exploração capaz de adaptar e persistir em ambientes onde é visível o predomínio das práticas de viés capitalista. Assim, deve-se buscar uma adaptação dos modos de produção tradicionalmente aplicados pela agricultura familiar às novas exigências da sociedade.

Dessa maneira, o modo de produção familiar ganha destaque para a analise de temas como a segurança alimentar e nutricional, através da possibilidade de maior diversidade de 
alimentos, em quantidade e qualidade apropriados, e o aprimoramento da relação homemalimento-sociedade, que vem sendo destruída pela modernidade.

\section{A IMPORTÂNCIA DA PRODUÇÃO DE ALIMENTOS}

Conforme a Constituição Federal Brasileira, em seu artigo $6^{\circ 1}$, o direito à alimentação é um direito social. Assim sendo, cabe ao Estado, como principal responsável pela implementação de direitos, assegurar a efetividade desse preceito a todos os cidadãos, através de políticas públicas que busquem fomentar os meios necessários para seu exercício² ${ }^{2}$

Se uma alimentação segura e permanente, tanto em termos de qualidade como em quantidade, é condição vital para a sobrevivência humana, possuir ou não previsão constitucional deveria ser percebido como mero detalhe. Haja vista que, além de compor um direito social, o direito à alimentação é um dos pontos primordiais do direito à vida (que é tido como cláusula pétrea em nossa Constituição Federal).

Assim, ao analisar o tema, não se deve restringir ao que se extrai do texto constitucional. Deve-se buscar uma conceituação mais completa, ou seja, o direito à alimentação não é exclusivamente o acesso a alimentos. $\mathrm{O}$ ser humano precisa muito mais que uma porção nutricionalmente balanceada, através da alimentação humana deve-se gerar humanidade, um processo de transformação de natureza (VALENTE, 2002).

Ao comer nos refazemos, nos construímos, nos potencializamos nas dimensões orgânicas, intelectuais, psicológicas e espirituais, enfim, somos o que comemos e como comemos (VALENTE, 2002). Assim, a fome (que consiste em uma negação ao direito à alimentação e a uma vida de qualidade melhor) seria uma negação à própria humanidade.

Segundo Valente (2002, p.39),

A sociedade brasileira convive atualmente com a existência das doenças associadas à pobreza e à exclusão, tais como a fome e a desnutrição, e aquelas associadas a hábitos alimentares inadequados que afetam mais gravemente as populações pobres, mas que também atingem duramente todas as outras parcelas da sociedade.

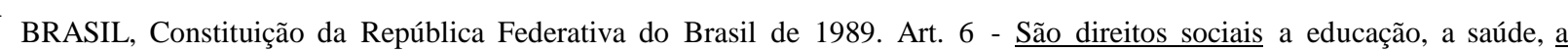
alimentação, o trabalho, a moradia, o lazer, a segurança, a previdência social, a proteção à maternidade e à infância, a assistência aos desamparados, na forma desta Constituição (grifo nosso).

2 A Lei 11.346 de 2006, no caput do artigo $2^{\circ}$, demonstra essa preocupação: “A alimentação adequada é direito fundamental do ser humano, inerente à dignidade da pessoa humana e indispensável à realização dos direitos consagrados na Constituição Federal, devendo o poder público adotar as políticas e ações que se façam necessárias para promover e garantir a segurança alimentar e nutricional da população".
} 
No contexto brasileiro, a carência alimentar e nutricional tem sua origem com a colonização no ano 1500 (VALENTE, 2002). E desde então, o tema foi pouco pesquisado e percebido com determinado temor pela esfera pública, prevalecendo ideias de autores como Malthus $^{3}$ e Vogt, que viam o tema com certo preconceito (ROCHA, 2011). No entanto, após os escritos de Josué de Castro, nasce uma nova visão sobre o tema ${ }^{4}$.

Segundo Rocha (2011, p. 33),

[...] Os estudos de Josué de Castro possibilitaram que a fome fosse conduzida à discussão pública como um problema social, que gerava exclusão.

A descoberta da fome foi o passo inicial em direção ao reconhecimento da alimentação como um direito.

No Brasil, atualmente, o tema do direito à alimentação, do ponto de vista legal, está disposto na Lei 11.346/2006, que cria o Sistema Nacional de Segurança Alimentar e Nutricional - SISAN, com o objetivo de assegurar o direito humano à alimentação adequada.

Conforme o artigo $3^{\circ}$, da Lei 11.346/2006, a segurança alimentar e nutricional é a realização do direito de todos ao acesso regular e permanente a alimentos de qualidade e em quantidade suficiente, oriundos de práticas alimentares saudáveis, que respeitem a diversidade cultural e que seja ambiental, cultural, econômica e socialmente sustentável. Garantir o direito à alimentação trata-se de construir um novo paradigma social, baseado na qualidade de vida do ser humano.

Assim, o modo de produção de alimentos tem ligação direta à relação do homem com seu meio e com a cultura na qual está imerso. Assim, cada dinâmica cultural desenvolve modos de alimentação que são construídos do cultivo ao consumo, permitindo que o preparo do alimento seja a tradução de práticas coletivas de cultivo, transformação e preparo (DERANI, 2006).

Atualmente a alimentação está cada vez mais limitada e pobre. No entanto, poucas pessoas percebem a relação existente entre os modelos agrícolas hegemônicos e o padrão

\footnotetext{
${ }^{3}$ Malthus afirmou que a população cresce em progressão geométrica (por multiplicação) e os recursos alimentares em progressão aritmética (por adição), o que conduz a humanidade a um impasse inevitável, cuja a única saída é a fome maciça, podando sem piedade os excessos de população que o mundo não poderia comportar (CASTRO, 2003)

${ }^{4}$ Em verdade, foi no período da redemocratização (fim do período da Ditadura Militar) que se iniciaram os debates que deram novo enfoque ao tema da fome. Foram os trabalhos de Hebert de Souza (o Betinho) com a criação da "Ação da Cidadania contra a Fome, a Miséria e pela Vida" que colocaram o problema da fome no centro da esfera política (ROCHA, 2011).
} 
alimentar que nos é apresentado que geram consequências socioambientais, desde a marginalização socioeconômica dos agricultores familiares até devastação de ecossistemas, por exemplo (SANTILLI, 2009).

A busca da garantia do direito à alimentação deve partir da construção de um novo paradigma de sociedade, em que o eixo principal seja a qualidade de vida do ser humano (VALENTE, 2002). Ou seja, deve-se estruturá-lo em uma lógica interna de reconhecimento recíproco, que objetiva garantir iguais liberdades para todos os indivíduos (ROCHA, 2011).

A segurança alimentar e nutricional, o desenvolvimento sustentável da agricultura, o combate à fome e miséria e a preservação ambiental estão diretamente ligados a essa mudança de conduta. Faz-se necessário compreender esse valor sociocultural da produção, transformação e consumo de alimentos.

Segundo Valente (2002, p.50),

É fundamental ampliar a produção nacional de alimentos, mesmo tendo em conta que as dificuldades de acesso continuam a ser o principal entrave à segurança alimentar no Brasil. Tal acréscimo, além de garantir a satisfação da demanda atual, $[\ldots]$ pode viabilizar e consolidar a agricultura familiar [...].

\section{DESENVOLVIMENTO DA AGRICULTURA BRASILEIRA - OS IMPACTOS DA MODERNIZAÇÃO}

O latifúndio e a monocultura destinada ao mercado externo, predominante no cenário agrícola, tem sua origem na forma colonial aplicada ao país. As grandes extensões de terra, agrupadas e intituladas como sesmarias pelo governo português, deixaram resquícios na cultura agrária até os dias atuais.

O processo de modernização da agricultura, empreendido a partir da década de 60 , principalmente pelos governos militares brasileiros, direcionou-se, com destaque, para a produção de commodities. Tal dinâmica trouxe benefícios aos produtores de latifúndios, impondo certo grau de especialização e tecnologia que provavelmente colaborou para que as culturas tidas como de "subsistência" perdessem espaço para a produção direcionada para a exportação, que atendiam os interesses do mercado mundial.

A visão do Regime Militar sobre o meio agrário encontra-se, sem dúvidas, estampado no Estatuto da Terra que, definiu os institutos e moldou as políticas de governo, bem como o próprio espaço social do campo. As políticas agrícolas a partir do golpe foram 
conduzidas para a transformação da propriedade agrária em um espaço de consumo e produção para o setor industrial.

As políticas públicas instituídas no Brasil, a partir da década de 60, procuraram responder aos desafios criados pela necessidade de modernização da agricultura brasileira, tida como "atrasada". Assim, esse período ficou conhecido como o principal momento de fusão dos interesses industriais com os da oligarquia rural. O Golpe Militar de 1964 significou o surgimento de um novo programa econômico, através de uma intervenção mais acentuada do governo no meio agrícola.

O objetivo era organizar o desenvolvimento do setor para evitar rupturas que pudessem colocar em risco a execução do processo de desenvolvimento econômico do país como um todo.

No entanto, tais alterações não poderiam ocorrer somente com a orientação do mercado. Deveriam estar concentradas nas mãos de uma entidade que tivesse poder para garantir a execução das medidas e possíveis correções necessárias, bem como possuir poder para conter as pressões e forçar decisões que atendam ao interesse de todos os envolvidos no sistema produtivo (GONÇALVES NETO, 1997).

Assim, o Estado brasileiro constituiu-se como o grande condutor do processo de desenvolvimento do país, sobre tudo através de suas ações de planejamento, execução e avaliação, tornando-se agente ativo nas realizações da economia. Com sua presença maciça na economia nacional, as ações do Estado passaram a ser o fio condutor do crescimento desejado.

Era necessário o desenvolvimento de todos os setores da economia para que o foco principal fosse alcançado. O desenvolvimento e modernização da agricultura era um ponto crucial para o projeto de industrialização e urbanização do país. Dessa maneira, coube ao setor agrícola fomentar as bases do surto industrial de substituição de importações vivida pelo país, fornecendo em especial capital e mão de obra excedente para tal crescimento (GONÇALVES NETO, 1997).

Assim, o objetivo do governo era atrelar o setor agrícola ao desenvolvimento econômico brasileiro, não permitindo que viesse atrapalhar o crescimento almejado. A canalização de recursos direcionados para o setor agrícola pretendia possibilitar a integração da agricultura ao circuito industrial.

O principal desafio do Estado brasileiro, então, seria conciliar os interesses do capital no campo e na cidade, sem permitir diminuição de espaço e poder do hegemônico setor urbano- 
industrial. As políticas públicas que vieram a ser aplicadas pós-64 tinham como escopo manter inalteradas as formas de acumulação dominante na sociedade.

Também, deve ser destacado que os reais beneficiários das políticas públicas de desenvolvimento do campo, a partir da década de 60, foram em sua grande parte os grandes produtores e os empresários do setor industrial. Isso, pois, ambos possuíam estrutura financeira para tal. O primeiro porque possuía ativo imobilizado e recursos para garantir o uso do crédito e o segundo, por ser o fornecedor das inovações (máquinas e implementos agrícolas, insumos, etc.) para a atividade agrícola (GONÇALVES NETO, 1997).

Assim, a partir desse período, notaram-se as mais profundas transformações do meio rural, juntamente com as mudanças na estrutura econômica que ocorreram na sociedade da época. A "revolução verde" constitui-se em um modelo agrícola caracterizado pela associação de insumos químicos (adubos e agrotóxicos), mecânicos (tratores, colheitadeiras mecânicas etc.) e biológicos (variedades melhoradas).

Segundo Juliana Santilli (2009), a homogeneização das práticas produtivas e a alta “artificialização" dos ecossistemas agrícolas, uma das principais características da "revolução verde", reduziram (e, em muitos casos, eliminaram) a diversidade de espécies e variedades de plantas cultivadas e de ecossistemas agrícolas existentes no planeta.

Com a "revolução verde", a produção de alimentos passa a compor a formação do capital, perdendo sua função originária que é a alimentação. Segundo Derani (2006), partindo dessa lógica, o tempo da produção deve ser o tempo do mercado, bem como a forma de produção deve buscar a melhor eficiência (ou seja, maior produtividade e maior lucro).

A partir dos anos 80, a consolidação desse processo de modernização da agricultura brasileira reduziu o alcance da agricultura familiar, ficando restrita a determinados nichos do mercado ou tendo que se integrar a indústria agroalimentar. Aos que permaneceram no campo restavam as seguintes alternativas: a) seguir para a fronteira agrícola; b) procurar sobreviver na área de origem, intensificando a produção ou c) buscar complementar a renda com outras formas produtivas (agrícolas ou não), fora da unidade familiar.

Assim, com esse cenário, desenvolveram-se no Brasil dois modelos de produção agrícola: a agricultura familiar (camponesa) e a agricultura patronal, ou mais conhecida como "agronegócio",5 que foi o principal beneficiário da modernização iniciada no meio rural.

As tecnologias introduzidas pela "Revolução Verde", apesar de serem consideradas pela maioria dos pesquisadores do tema como a opção tecnológica mais eficiente, em razão do 
alto custo de sua implementação, seu acesso ficou inviável para a grande maioria dos agricultores familiares (GUANZIROLI, 2001).

Segundo Valente (2002, p.51),

A política atual do governo brasileiro é a de buscar compatibilizar segurança alimentar e liberalização comercial. [...] o maior risco dessa política [...] é o de deixar os pequenos e médios produtores rurais à mercê das condições de extrema competitividade do mercado internacional, permeado por práticas comerciais desleais [...].

No entanto, apesar da exclusão da agricultura familiar desse processo de modernização do campo, tem-se percebido que o modo de produção familiar constitui uma maneira de exploração capaz de adaptar e persistir em ambientes onde é visível o predomínio das práticas de viés capitalista. Permitindo o aumento da diversidade na produção de alimentos e desenvolvimento de novos modos de produção com viés sustentável.

\section{PAPEL DA AGRICULTURA FAMILIAR PARA O RESGATE DA DIVERSIDADE}

O modelo de desenvolvimento baseado meramente em condições econômicas (predominante no cenário agrícola brasileiro) deixa a mercê os agricultores familiares que dispõem de poucos fatores de produção (terra, mão de obra e capital). Assim, por não conseguirem acompanhar a evolução da modernização, os agricultores familiares acabaram se localizando nesse processo a margem dos benefícios existentes para o desenvolvimento da agricultura.

Apesar do processo de exclusão desenvolvido durante o processo de modernização do campo no país, os agricultores familiares não constituem personagens novos no cenário econômico. Apesar de não terem acompanhado o processo de modernização, percebe-se que o modelo de produção aplicado por esses produtores constitui uma maneira de exploração capaz de adaptar e permanecer em ambientes de predomínio capitalista.

\footnotetext{
${ }^{5} \mathrm{O}$ agronegócio se caracteriza pela produção baseada na monocultura, especialmente de produtos cujos valores são ditados pelas regras do mercado internacional (soja, milho, trigo, algodão, café etc.), pela utilização intensiva de insumos químicos e de máquinas agrícolas, pela adoção de pacotes tecnológicos (que, mais recentemente, incluem as sementes transgênicas), pela padronização e uniformização dos sistemas produtivos, pela artificialização do ambiente e pela consolidação de grandes empresas agroindustriais (SANTILLI, 2009).
} 
De uma maneira geral, a agricultura familiar sempre teve como característica básica a policultura (plantações de milho, feijão, arroz, etc. e o cultivo de hortaliças e frutíferas), constituindo-se, com o tempo, uma diversidade de formas sociais, sendo difícil estabelecer um modelo padrão para esse tipo de produção (SANTILLI, 2009).

Em síntese, a agricultura familiar, caracterizada pelo entrelaçamento da família, produção e trabalho, possui características próprias, visíveis em sua atuação econômica e social. Para lidar com as demandas do presente e do futuro que lhe são apresentadas, o agricultor familiar recorre aos ensinamentos do passado, um saber tradicional, que pode ser transmitido aos seus filhos, sendo a justificativa central das decisões tomadas no planejamento de suas atividades (WANDERLEY, 2001).

O agricultor familiar não é originário de uma construção anterior ao capitalismo. Tratase de uma criação realizada pelo próprio sistema. Sua relação com a terra não é puramente capitalista, há também um viés social.

Não restam dúvidas que os sujeitos dessa agricultura familiar não constituem figuras novas no contexto social contemporâneo, apesar de lidarem com elementos tradicionais, devendo-se adaptar às condições modernas de produção, haja vista que estão inseridos no mercado moderno e, também, são influenciados pela sociedade e pelo Estado (WANDERLEY, 2001).

O mundo rural trata-se de um universo socialmente integrado ao conjunto da sociedade brasileira e ao contexto atual das relações internacionais (WANDERLEY, 2001). Assim, caberá aos agricultores familiares enfrentarem os desafios modernos sem deixarem de lado todo o aprendizado adquirido ao longo dos anos.

As transformações necessárias ao chamado agricultor familiar moderno não se caracterizam como uma ruptura total e definitiva com seus valores e tradições anteriores, mas uma adaptação às novas exigências da sociedade (WANDERLEY, 2001).

O modo de produção familiar é fundamental para a segurança alimentar e nutricional, através da maior diversidade de alimentos e da possibilidade de aprimoramento da relação homem-alimento-sociedade, que vem sendo destruída pela modernidade. Além disso, gera emprego e renda e possibilita o desenvolvimento local em bases sustentáveis e equitativas (SANTILLI, 2009).

Para ressaltar a importância da agricultura familiar para a produção de alimentos, cabe observar alguns dados apresentados pelo Censo Agropecuário de $2006^{6}$. 
Os estabelecimentos $^{7}$ de agricultores familiares representam $84,4 \%$ dos estabelecimentos brasileiros, ocupando uma área de 80,25 milhões de hectares $(24,3 \%)$, no entanto, os estabelecimentos não familiares, apesar de representarem 15,6\% do total dos estabelecimentos, ocupavam 75,7\% da área ocupada (FRANÇA, 2009). Comprovando a caraterística latifundiária do meio rural brasileiro.

Segundo o Caderno da Agricultura Familiar do Censo, dos 80,25 milhões de hectares da agricultura familiar, apenas $22 \%$ são ocupadas com lavouras. (FRANÇA, 2009). No entanto, pode-se observar a enorme variedade das culturas produzidas:

[...]87\% da produção nacional de mandioca, $70 \%$ da produção de feijão (sendo $77 \%$ do feijão-preto, $84 \%$ do feijão-fradinho, caupi, de corda ou macáçar e $54 \%$ do feijão-de-cor), $46 \%$ do milho, $38 \%$ do café (parcela constituída por $55 \%$ do tipo robusta ou conilon e $34 \%$ do arábica), 34\% do arroz, 58\% do leite (composta por 58\% do leite de vaca e $67 \%$ do leite de cabra), possuía 59\% do plantel de suínos, $50 \%$ do de aves, $30 \%$ dos bovinos, e produzia $21 \%$ do trigo. A cultura com menor participação da agricultura familiar foi a soja (16\%), um dos principais produtos da pauta de exportação. (FRANÇA, 2009, p.26).

Confirmando-se, assim, que a agricultura familiar é responsável por garantir boa parte do fornecimento de alimentos para o mercado interno.

O modo de produção familiar é fundamental para a segurança alimentar e nutricional, através da maior diversidade de alimentos e da possibilidade de aprimoramento da relação homemalimento-sociedade, que vem sendo destruída pela modernidade. Além disso, gera emprego e renda e possibilita o desenvolvimento local em bases sustentáveis e equitativas (SANTILLI, 2009).

\footnotetext{
${ }^{6}$ O conceito de "agricultura familiar", adotado pelo Censo Agropecuário (por conta da demanda do Ministério do Desenvolvimento Agrário), está previsto na Lei n. 11.346/06, que estabelece as diretrizes para a formulação da Política Nacional da Agricultura Familiar e Empreendimentos Familiares Rurais, em seu artigo. $3^{\circ}$. Para ser classificado como de "agricultura familiar" precisava atender simultaneamente a todas as condições previstas em lei.

${ }^{7}$ O Censo 2006 considerou como estabelecimento agropecuário "toda unidade de produção dedicada, total ou parcialmente, a atividades agropecuárias, florestais e aquiícolas, subordinada a uma única administração: a do produtor ou a do administrador. Independente de seu tamanho, de sua forma jurídica ou de sua localização em área urbana ou rural, tendo como objetivo a produção para subsistência e/ou para venda, constituindo-se assim numa unidade recenseável". As áreas não-contínuas, exploradas por um mesmo produtor, foram consideradas como um único estabelecimento, desde que estivessem situadas no mesmo setor censitário, utilizassem os mesmos recursos técnicos (máquinas, implementos e instrumentos agrários, animais de trabalho, etc.) e os mesmos recursos humanos (o mesmo pessoal), e, também, desde que estivessem subordinadas a uma única administração: a do produtor ou a do administrador.
} 


\section{ATUAÇÃO DO ESTADO NO DESENVOLVIMENTO DA AGRICULTURA FAMILIAR E O INCREMENTO DA PRODUÇÃO}

Dentre as atividades do Estado para o desenvolvimento da agricultura familiar e o incremento da produção, cabe destaque o Programa Nacional de Fortalecimento da Agricultura Familiar (Pronaf) $^{8}$. Em 1996, objetivando atender a reivindicação das organizações dos trabalhadores rurais, pela formulação e a implantação de políticas de desenvolvimento rural específicas para a agricultura familiar, foi criado o Programa.

A criação do Pronaf foi uma resposta à conclusão de que nada adiantaria um programa de reforma agrária destinada a ampliar o número de produtores familiares se os existentes estavam saindo do campo por falta de apoio (GUANZIROLI, 2001). Além disso, o Programa resultou do aprimoramento da Política de Valorização da Pequena Produção (PROVAP), criado em 1994, ainda no Governo Itamar Franco.

Segundo Mattei (2006, p. 13),

[...] neste processo os atores sociais rurais, através de suas organizações e de suas lutas, desempenharam um papel decisivo na implantação do programa, considerado uma bandeira histórica dos trabalhadores rurais, pois permitiria a estes o acesso aos diversos serviços oferecidos pelo sistema financeiro nacional, até então negligenciados aos agricultores familiares.

Criado durante o governo de Fernando Henrique Cardoso, o Pronaf objetivava estimular a geração de renda e melhorar o uso da mão de obra familiar, por meio do financiamento de atividades e serviços rurais agropecuários e não agropecuários desenvolvidos em estabelecimento rural ou em áreas comunitárias próximas.

Devido às inúmeras mudanças pelo qual passou desde seu surgimento, o Pronaf adquiriu, com o tempo, relativa importância para a agricultura familiar brasileira, principalmente, a partir da segunda metade da década de 1990. Atualmente, segundo o Plano Safra 2015/2016, o investimento na agricultura familiar, através do Pronaf, será de R\$ 28,9 bilhões ${ }^{9}$.

\footnotetext{
${ }^{8}$ Criado pelo Decreto n. 1946/1996 (modificado, atualmente, pelo Decreto n. 3508/2000).

9 Informação obtida em: <http://www.brasil.gov.br/economia-e-emprego/2015/07/agricultura-familiar-produz70-dos-alimentos-consumidos-por-brasileiro>
} 
No entanto, nota-se que o aumento do interesse pelo crescimento e modernização da agricultura familiar tem um viés compensatório. As políticas públicas direcionadas para a agricultura familiar buscam sua adaptação aos anseios do mercado, que, atualmente, é o responsável por orientar os caminhos do agronegócio.

Entretanto, as políticas públicas para o setor não devem ser concebidas para reduzir os efeitos danosos de estratégias e políticas macroeconômicas e setoriais, que não conduziram a um desenvolvimento com equidade (BUAINAIN; ROMEIRO; GUANZIROLI, 2003). O fortalecimento e o desenvolvimento da agricultura familiar para ser alcançado requer a integração das políticas macroeconômica, agrícola e de desenvolvimento rural, de forma a reduzir os atritos e aumentar a convergência entre os diversos níveis de intervenção do setor público (BUAINAIN; ROMEIRO; GUANZIROLI, 2003).

Conforme o Censo Agropecuário, após o período de 1999, observou-se um crescimento progressivo nos contratos firmados, ou seja, um número maior de agricultores familiares vem tendo acesso ao crédito rural (MATTEI, 2005). No entanto, o Pronaf ainda não se tornou uma política efetiva de apoio ao desenvolvimento rural em todas as regiões do país.

Percebe-se que a região Sul continua concentrando $47 \%$ do total dos recursos do programa, enquanto que a região Nordeste diminuiu sua participação de 26\%, em 1999, para $18 \%$ na última safra agrícola, mesmo que um maior número de agricultores tenha tido acesso ao crédito rural (MATTEI, 2005).

Outro ponto restritivo do Programa está nos limites apresentados pelo sistema financeiro. Conforme previsão do Manual do Crédito Rural 10-1-8, as garantias necessárias para o fornecimento do crédito é de livre convenção entre o financiado e o financiador. Assim, bancos tendem a trabalhar com seus próprios clientes, criando obstáculos aos demais que não possuam garantias adequadas às suas demandas de crédito (MATTEI, 2005).

Sabe-se que um dos principais problemas relacionados à agricultura familiar está ligado ao fator financeiro. Inversamente a ideia de atraso e baixa produtividade que é vincula ao modo de produção familiar, há partes dessa agricultura que maneja sistemas produtivos modernos que utilizam intensivamente os insumos adquiridos no mercado (BUAINAIN; ROMEIRO; GUANZIROLI, 2003). 
Assim, a ausência de recursos (seja pela insuficiência de oferta de créditos ou por relações contratuais nada vantajosas) causam restrições ao funcionamento desse modelo de produção familiar moderno, mitigando a sua capacidade de manter-se competitiva em um mercado cada vez mais agressivo e exigente (BUAINAIN; ROMEIRO; GUANZIROLI, 2003).

Apesar das dificuldades quanto à distribuição dos recursos do Pronaf, conforme o Censo Agropecuário de 2006, houve um incremento na produção de alimentos nas regiões beneficiadas:

[...] nota-se que 72 municípios [...] tiveram aumento da área colhida com lavouras temporárias, fato que está associado ao apoio dado pelo programa, especialmente pela disponibilidade de crédito aos diferentes segmentos de agricultores familiares. Especialmente em relação aos municípios da região Sul [...], verifica-se que 74\% deles expandiram a área colhida. Ainda, 95\% dos municípios paranaenses presentes entre os cem maiores tomadores de crédito tiveram aumento da área colhida, o que pode estar associado aos mecanismos de financiamento da produção disponibilizados pelo programa. (MATTEI, 2005, p. 66).

Vale ressaltar que, para que haja o bom desempenho da agricultura familiar é necessário um conjunto amplo de condicionantes, que vão desde a disponibilidade de recursos, a inserção socioeconômica, a localização geográfica, as oportunidades e a conjuntura econômica, as instituições e valores culturais da família, do grupo social e até mesmo do país (BUAINAIN; ROMEIRO; GUANZIROLI, 2003). Assim, o crescimento e a consolidação da agricultura familiar, bem como a melhoria da produção de alimentos, dependem de políticas e instrumentos que agreguem tais requisitos.

\section{CONCLUSÃO}

Os inúmeros avanços tecnológicos que o meio agrícola recebeu nos últimos anos, através da "revolução verde", objetivando aumentar a quantidade e qualidade dos produtos, geraram sérias preocupações quanto à efetividade do direito à alimentação.

No caso brasileiro, a partir da década de 60, houve uma alteração no modelo produtivo de alimentos, reduzindo a diversidade de produtos e comprometendo o desenvolvimento da relação homem-alimento-sociedade. 
Assim, em detrimento de um modelo produtivo latifundiário e monocultor, a produção de alimentos, que tem ligação direta à relação do homem com seu meio e com a cultura na qual está imerso, comprometeu a efetividade do direito à alimentação.

A produção industrial de alimentos, que gera o distanciamento nas relações pessoais de convívio, tem comprometido o valor sociocultural da produção, transformação e consumo de alimentos. Também, nota-se uma redução na variedade dos próprios alimentos produzidos, pois, o modelo modernamente aplicado não valoriza essa diversidade.

As políticas públicas direcionadas à produção de alimentos corroboram, cada vez mais, para o sucesso e predomínio da "revolução verde", que se constituiu em um modelo agrícola caracterizado pela associação de insumos químicos, mecânicos e biológicos.

O Pronaf, principal Programa governamental para o desenvolvimento da agricultura familiar, apesar das distorções existentes na distribuição do crédito fornecido, tem contribuído para o incremento da produção. Porém, não se percebe um incentivo para a consolidação de novas práticas produtivas, mais efetivas quanto ao direito à alimentação.

No entanto, a agricultura familiar, com seu modelo produtivo baseado em práticas que valorizam a diversidade da produção, é capaz de reverter esse cenário. Ou seja, consistiria em uma maneira de exploração capaz de adaptar e persistir em ambientes com o predomínio das práticas de viés capitalista, adaptando-se às novas exigências da sociedade (efetividade do direito à alimentação, o desenvolvimento sustentável do agrícola, o combate à fome e miséria e a preservação ambiental).

Apesar de ser uma criação realizada pelo próprio sistema capitalista, a relação do agricultor familiar com a terra não é puramente capitalista, há também um viés social. Assim, há a possibilidade de se alcançar uma maior diversidade de alimentos, bem como o aprimoramento da relação homem-alimento-sociedade, que vem sendo destruída pela modernidade.

\section{REFERÊNCIA BIBLIOGRÁFICA}

BANCO CENTRAL DO BRASIL. Manual de Crédito Rural. Brasília, 2015.

BRASIL. Constituição da República Federativa do Brasil de 1988. Disponível em: <http://www.planalto.gov.br/ccivil_03/constituicao/constituicaocompilado.htm> acesso dia $15 / 01 / 2015$. 
Decreto $\mathrm{n}^{\circ} 1.946$ de 28 de junho de 1996. Cria o Programa Nacional de Fortalecimento da Agricultura Familiar - PRONAF, e dá outras providências. Disponível em: < http://www.planalto.gov.br/ccivil_03/decreto/D1946.htm >, acessado dia 01/07/2015.

Lei $n^{\circ}$ 11.346, de 15 de setembro de 2006. Cria o Sistema Nacional de Segurança Alimentar e Nutricional - SISAN com vistas em assegurar o direito humano à alimentação adequada e dá outras providências. Disponível em: <http://www.planalto.gov.br/ccivil_03/_ato2004-2006/2006/lei/111346.htm> acesso dia $15 / 01 / 2015$.

CASTRO, Josué; CASTRO, Anna Maria de (org.). Fome: um tema proibido - últimos escritos de Josué de Castro. Rio de Janeiro: Civilização Brasileira, 2003.

DERANI, Cristiane. Alimento e biodiversidade: fundamentos de uma normatização. Hiléia: Revista de Direito Ambiental da Amazônia. Manaus, Ano 3, nº 4, p. 53 - 86, 2006.

FRANÇA, Caio Galvão de. O censo agropecuário 2006 e a agricultura familiar no Brasil. Brasília: Ministério do Desenvolvimento Agrário, 2009.

GONÇALVES NETO, Wenceslau. Estado e agricultura no Brasil: políticas públicas e modernização econômica Brasileira - 1960-1980. São Paulo: Editora Hucitec, 1997.

GUANZIROLI, Carlos et al:: Agricultura Familiar e Reforma Agrária no Século XXI. Rio de Janeiro: Garamond, 2001.

IBGE. Censo Agropecuário 2006 - Agricultura familiar: primeiros resultados. Rio de Janeiro: 2006.

MATTEI, Lauro. Impactos do Pronaf: análise de indicadores. Brasília: Ministério do Desenvolvimento Agrário, Núcleo de Estudos Agrários e Desenvolvimento Rural, 2005.

Pronaf 10 anos: mapa da produção acadêmica. Brasília: Ministério do Desenvolvimento Agrário, 2006. 
ROCHA, Eduardo G. Direito à alimentação: teoria constitucional-democrática e políticas públicas. São Paulo: LTr, 2011.

SANTILLI, Juliana. Agrodiversidade e direitos dos agricultores. São Paulo: Peirópolis, 2009.

VALENTE, L.S.V. Direito humano à alimentação: desafios e conquistas. São Paulo: Cortez editora, 2002.

WANDERLEY, Maria de Nazareth Baudel. A emergência de uma nova ruralidade nas sociedades modernas avançadas - o "rural" como espaço singular e ator coletivo. Disponível em:

<http://bibliotecavirtual.clacso.org.ar/ar/libros/brasil/cpda/estudos/quinze/nazare15.htm> acesso em 20/01/2015

Raízes históricas do campesinato brasileiro. In; TEDESCO, J. C. (Org.). Agricultura familiar: realidades e perspectivas. 3. ed. Passo Fundo: UPF, 2001. p. 21-55

A ruralidade no Brasil moderno. Por um pacto social pelo desenvolvimento rural. Disponível em: <http://biblioteca.planejamento.gov.br/biblioteca-tematica1/textos/desenvolvimento-agrario/texto-29-a-ruralidade-no-brasil-moderno.pdf> acesso em $19 / 01 / 2015$. 